\title{
HIDROLOJİK MODELLEMEDE CBS VE UA TEKNIKKLERINIIN KULLANILMASI
}

\author{
Alper UĞURLUOĞLU ${ }^{1}$, Ali Arda ŞORMAN²
}

${ }^{1}$ Uzman, Su Yönetimi Genel Müdürlüğü, İzleme ve Su Bilgi Sistem, Daire Başkanlığı, Ankara, augurluoglu@ormansu.gov.tr ${ }^{2}$ Dr.Öğr.Üyesi, Eskișehir Teknik Üniversitesi, İnşaat Mühendisliği Bölümü, Eskișehir, asorman@anadolu.edu.tr

\begin{abstract}
ÖZET
Su yönetiminin sağlanması; hidrolojik, ekolojik, ekonomik açıdan birlikte ve uyum içerisinde değerlendirilmesiyle havza bazında sürdürülebilir olarak gerçekleştirilebilmektedir. Su yönetimi uygulamalart çerçevesinde tüm bileșenlerin temelinde yer alan hidrolojik modelleme çalışmaları, karar destek sistemlerinin ayrı düşünülmez bir parçasıdır. Karar vericilere karar alma süreçlerinde bilimsel bir destek sunan hidrolojik modeller, senaryo bazlı tahminlemeler yoluyla yatırımların, problemlerin çözümünün mevcut durumlarının korunması ve iyileştirilmesine yönelik tedbirlerin alınmasında önemli yer tutmaktadır.

Bu çalıșmanın amacı, Türkiye'nin ekosistem açısından önemli sulak alanlarından olan Manyas Gölü'nün Yukarı Havzası'nda $H B V$ modeli ile gerçekleştirilen hidrolojik modelleme çalışması çıktılarından olan toprak nemi ve karla kaplı alan verilerinin uzaktan algılama yöntemleriyle karşılaştırmasını içermektedir. Toprak nemi olarak Avrupa Orta Ölçekli Hava Tahminleri Merkezi'nin (ECMWF) ve karla kaplı alan için Amerikan Ulusal Okyanus ve Atmosfer Dairesi'nin (NOAA) ürettiği uydu görüntülerinden faydalanılarak çalışma havzasında 2012-2015 su yıllarını kapsayan doğrulama analizleri yapılmıştır. Sonuçlara göre hidrolojik model çıtıları ve uydu verileri arasında başarılı bir uyum olduğu, bu durumun da güvenilir model parametreleri seçildiğini ortaya koymaktadır.
\end{abstract}

Anahtar Sözcïkler: hidrolojik modelleme, kar kaplı alan, toprak nemi, uzaktan algılama

\section{ABSTRACT \\ USE OF GIS AND REMOTE SENSING TECHNIQUES ON HYDROLOGICAL MODELING}

Water management can be realized as basin-based sustainable with the compatible evaluation of hydrological, ecological, and economical aspects together. Hydrological modeling studies that are the basis of all components within the framework of water management implementations cannot be considered as separate parts of decision support systems. Hydrological models that provide scientific support to decision makers during the decision processes play an important role in taking precautions to preserve and improve current situation of solution of problems and investments through scenario-based estimations.

The purpose of this study is to compare soil moisture and snow covered area data that are the outputs of hydrological modeling studies performed upstream of Manyas Lake, which is one of the most important wetland areas in terms of ecosystem in Turkey, by the HBV model with remote sensing methods. Validation analyses covering the 2012-2015 water years were conducted using satellite images generated by the European Centre for Medium-Range Weather Forecasts (ECMWF) for soil moisture and the National Oceanic and Atmospheric Administration (NOAA) for snow covered area. With regard to the results, there is a successful integration between hydrological model outputs and satellite data that reveals the parameters chosen for this study are reliable.

Keywords: hydrological modeling, remote sensing, snow covered area, soil moisture

\section{GİRIŞ}

Suyun öneminin arttığı günümüzde hidrolojik bileşenlerin dağılımının ortaya konması, bir çalışma alanı içerisinde suyun miktarına yönelik belirli bir sorunun çözülmesi veya durum tespitinin yapılması, günden güne artan hidrolojik modelleme çalışmaları aracılığıyla yapılabilmektedir.

Yirminci yüzyılın son çeyreğiyle birlikte havza ölçeğinde su yönetimi ön plana çıkarak bütüncül bir yaklaşımla mevcut durum ortaya konulmakta ve problemlere çözüm aranmaktadır. 1900'lü yıllardan bu yana geliştirilmekte olan metotlar, günümüzde gerek paket ürün yazılımlar gerekse açık kaynak kodlu hidrolojik modeller halinde geliştirilmiş olarak kullanılmaktadır. Hidrolojik sistemlerin karmaşıklığı, detaylarıyla anlaşılamaması ve sistem davranışı tepkileri modeller aracılığıyla çözümlenebilmektedir. (Xiong ve Guo, 1999)

Havza bazlı hidrolojik modellemenin iki temel amacı bulunmaktadır. Birincisi, sistemin işleyişi ve sistemdeki değişikliklerin etkilerinin daha iyi anlaşılabilmesidir. İkincisi ise tahmin ve tasarımlar için zaman serileri üretilmesidir. 
Bununla birlikte, hidrolojik modellemenin uygulamadaki amaçları suyun yönetimine dair gerçekleştirilen çalışmaların uhdesinde aşağıdaki gibi detaylandırılabilmektedir (Chong-yu, 2006).

- Su kaynaklarının kullanılabilirliğin artııılması amacıyla yapılan barajların, tesislerin planlanması, işletilmesi, geliştirilmesi gibi konularda ihtiyaç duyulan verinin geleceğe yönelik tahmin edilmesi,

- Ölçüm verisi bulunmayan havzalarda hidrolojik verinin üretilmesi,

- Havzalardaki arazi kullanımı değişikliği, iklim değişikliği gibi değişimlerin havzaya etkisinin ortaya konulması,

- Su tahsisinin sektörel bazda sağlanması amacıyla su bütçelerinin hesaplanması ile miktarın yönetilmesi ve tahminlenmesi,

- Yerüstü sularında su kalitesinin değerlendirilmesine yönelik kütle dengesi çalışmalarında kullanılacak akımların belirlenmesi ve tahminlenmesi,

- Doğal afet olarak sayılan kuraklık ve taşkın gibi hidrolojik olayların tahminlenmesi gibi amaçlarla hidrolojik modelleme çalışmaları gerçekleştirilmektedir.

$\mathrm{Bu}$ bağlamda, çalışmanın temelini oluşturan havza çıkarımı ve mekânsal analizler CBS platformunda gerçekleştirilmiş olup 2012-2015 yılları arasında Manyas Gölü Yukarı Havzası'nda gerçekleştirilen hidrolojik modelleme çalışmasından elde edilen toprak nemi ve karla kaplı alan verilerini uzaktan algılama yöntemleriyle karşılaştırmaktadır. Bu çalışma, hidrolojik modellerin doğrulanması ve güvenilirliğine ilişkin uzaktan algılama verilerinin önemini ortaya koymaktadır.

\section{MODEL ÇALIŞMALARI}

Hidrolojik Modelleme çalışmaları yirminci yüzyılın başlarından günümüze kadar pek çok alanda gerçekleştirilerek literatürde yerini almıştır.

Slovenya'nın en büyük nehirlerinden olan Sava Nehri'nin havzası Primožič ve Ark. (2008) tarafından İsveç menşeili HBV model ile modellenmiştir. $10.700 \mathrm{~km}^{2}$ havza alanına sahip Sava Nehir Havzası, Danube Nehri'nin de önemli kollarındandır. Model, 26 alt havza oluşturularak günlük kalibrasyona göre yapılandırılmıştır. 1990-2006 yıllarında koşturulan model 1990-1999 yılları arasında kalibre edilmiştir. 2000-2006 yılları validasyon amaçlı kullanılmıştır. Ortalama 0.86-0.90 model verimi elde edilmiştir.

Normand ve ark. (2010) tarafından HBV modeli, Doğu Nepal'deki Tamor havzasında 1987-1996 yılları arasında çalıştırılıp GAP (genetic algorithm package) optimizasyon yöntemi ile kalibre edilmiştir. \%69 oranında model verimi elde edilen çalışmada düşük akışların iyi simüle edildiği ortaya konmuştur. Pik akışların yakalanmasında model verimi \%62'lere düşmüş olup düşük akışlara göre daha az bir uyum söz konusu olmaktadır.

\section{1.Çalışma Alanı}

$\mathrm{Bu}$ çalışma kapsamında, hidrolojik modelleme uygulamasının sağlıklı ve doğru bir yaklaşım içerisinde gerçekleştirilebilmesi amacıyla antropojenik etkinin olmadığı veya çok az görüldüğü bir havza olarak Manyas Baraj Gölü Yukarı Havzası seçilmiş̧ir.

Çalışma alanı olarak belirlenen Manyas Gölü Yukarı Havzası, idari olarak Balıkesir ilinin Bandırma ve Manyas sınırları içerisinde bulunan Manyas Gölü'ne drene olan akarsuların oluşturduğu ve coğrafi koordinatları $40^{\circ} 10^{\prime}$ Kuzey, $28^{\circ} 00^{\prime}$ Doğu arasında kalan alanı kapsamaktadır. Çalışma alanına ait yer bulduru haritası Şekil 1'de verilmektedir. 


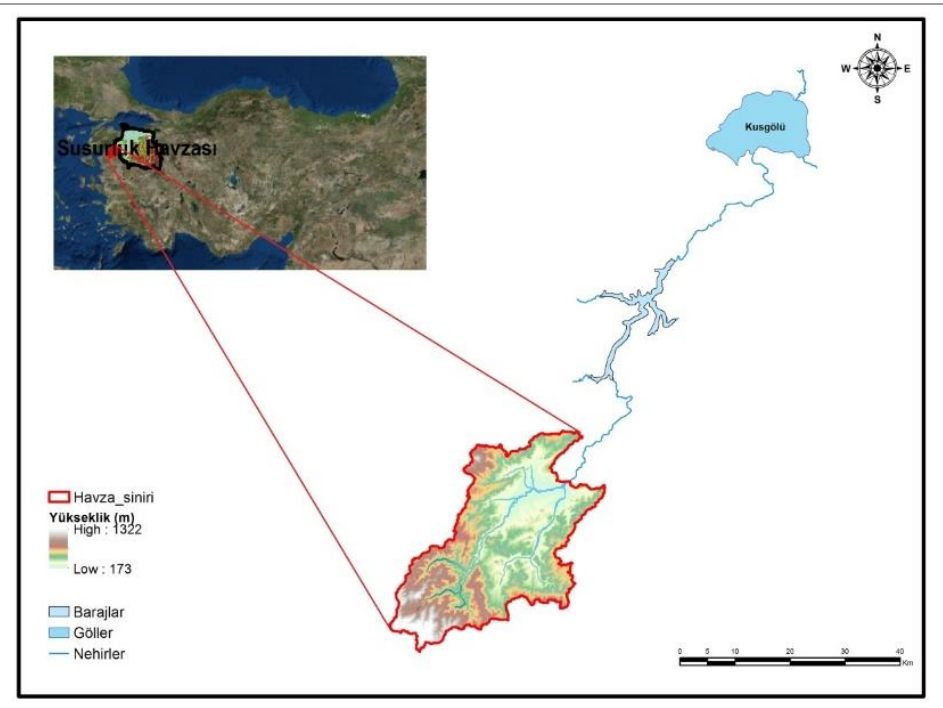

Şekil 1. Çalışma Alanı.

\subsection{HBV Modeli}

Bu çalışmada kullanılan HBV modeli (Bergström, 1976) ilk olarak 1970’lerde İsveç Meteoroloji ve Hidroloji Enstitüsü (SMHI)'nde yer alan "Hydrologiska Byrans Vattenavdelning" biriminde havzadaki akışın modellenmesi amaçlı olarak kullanılmaya başlanmıştır. Geçen yıllar boyunca HBV modeli İsveç Meteoroloji ve Hidroloji Enstitüsü (SMHI) tarafından geliş̧irilmekte olup (Bergström ve Lindström, 2015) akış simülasyonu amaçlı yaygınca kullanılmaktadır. Bununla birlikte, HBV ve modifiye versiyonları yaklaşık 45 ülkede uygulanmaktadır (Bergström ve Lindström, 2015).

HBV modeli içindeki çalışma akış diyagramı sırasıyla kar modülü, toprak modülü, yeraltı suyu modülü ve akım modülü olarak Şekil 2'de yer alan akış diyagramında görülmektedir.

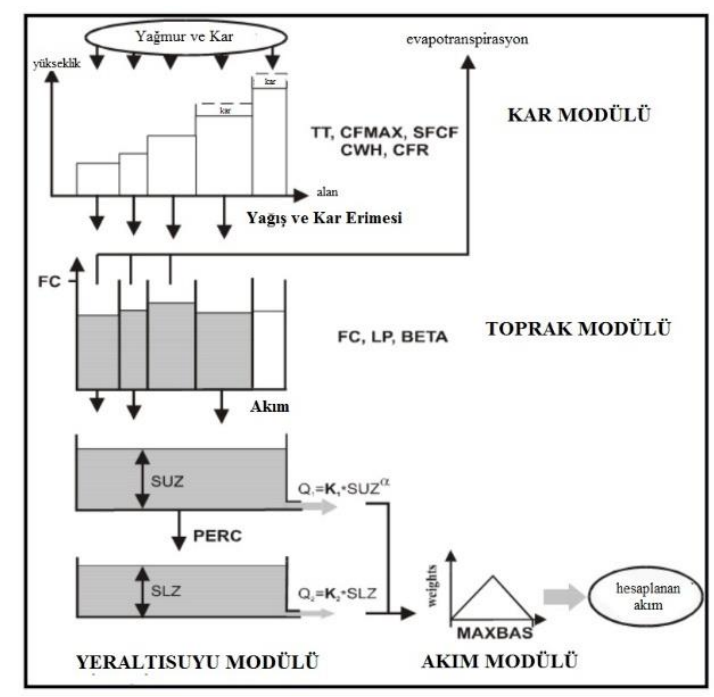

Şekil 2. HBV akış diyagramı.

\subsection{Model Girdileri}

HBV modeli, yağış $[\mathrm{mm} / \Delta \mathrm{t}]$, sıcaklık $\left[{ }^{\circ} \mathrm{C}\right]$ ve akım değerlerini $[\mathrm{mm} / \Delta \mathrm{t}]$ içeren tarihsel verileri, buharlaşma verisi ise $[\mathrm{mm} / \Delta \mathrm{t}]$ uzun dönemli aylık ortalama değerlere ihtiyaç duymaktadır. Farklı zaman serileri (saatlik, günlük, mevsimlik) gibi zaman adımlarında veri kabul edilen model ile gerçekleştirilen bu çalışmada günlük veriler kullanılmıştır. 
Türkiye'de hidrometeorolojik verilerinden sorumlu olan kurumlar Devlet Su İşleri Genel Müdürlüğü (DSİ) ve Meteoroloji Genel Müdürlüğü (MGM)'dür. Bu çalışma kapsamında gerekli olan veriler söz konusu kurumlardan temin edilmiştir. Çalışma alanı olan Manyas Gölü Yukarı Havzası'nın konumu göz önüne alınarak MGM veri tabanlarında, veri temin edilebilecek 9 adet gözlem istasyonu tespit edilmiştir (Şekil 3a). DSİ tarafından işletilen Akım Gözlem İstasyonlarında (AGİ) toplanan günlük akım verileri, havza içerisinde yer alan, hâlihazırda açık olan ve veri bulunan AGİ'ler araştırılarak 3 adet istasyondan elde edilmiştir.(Şekil 3b).

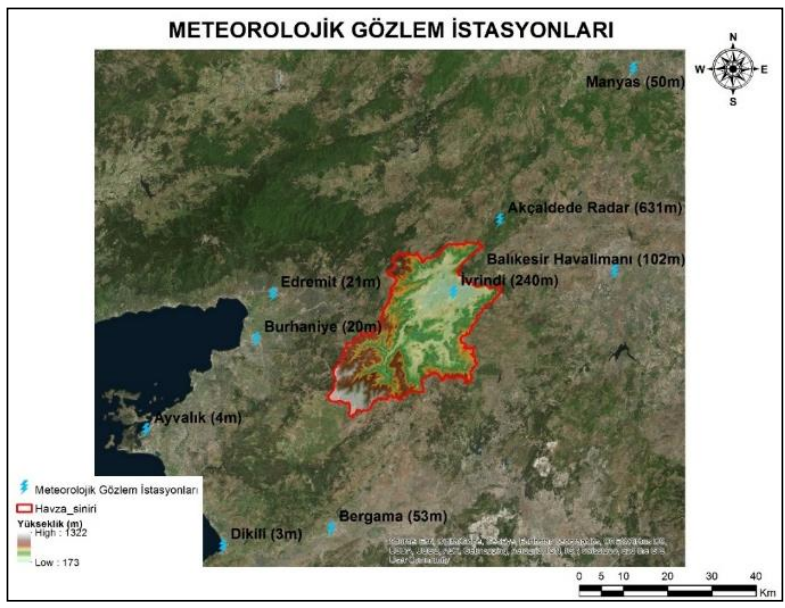

(a) Çalışma alanına ait meteorolojik gözlem istasyonları

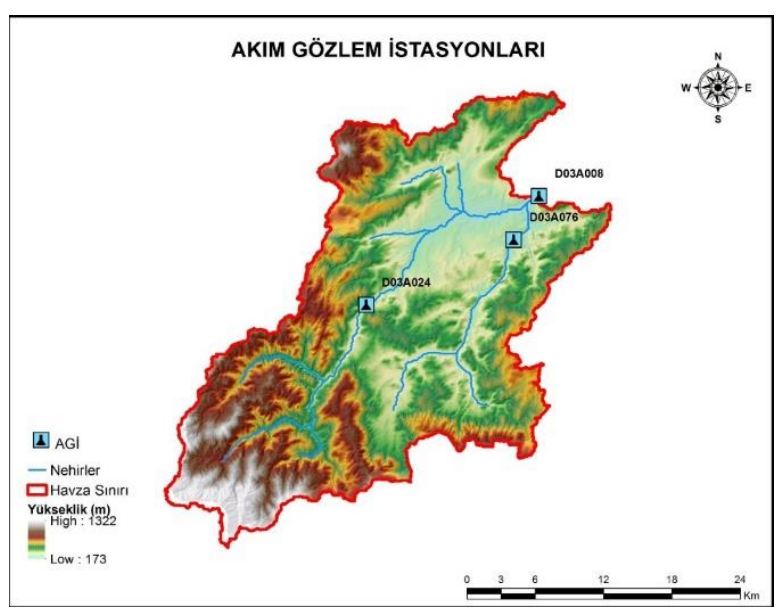

(b) Çalışma alanina ait akım gözlem istasyonları

Şekil 3.Çalışma alanında yer alan hidrometeorolojik istasyonlar.

Bu çalışma kapsamında, Manyas Gölü Yukarı Havzası Eş Yükselti haritası oluşturularak CBS ortamında alana ait veriler hesaplanarak modelin yarı dağılımlı olarak kullanılması sağlanmıştır. Elde edilen verilerin havzaya etkisi ölçeğinde incelenmesi sonucunda Şekil 3 (a)da tespit edilen meteorolojik istasyonların, havzayı en iyi temsil edeceği kabul edilen güneyde Bergama, batıda Burhaniye ve doğuda Balıkesir Havalimanı istasyonları kullanılmıştır

\subsection{Kalibrasyon ve Validasyon}

Kalibrasyon; girdilerin matematiksel eşitlikler kullanılarak çıktılara dönüştürülmesiyle, girdi-çıktı uyumunun matematiksel eşitlikleri oluşturan ve model parametreleri adı verilen parametrelerin üzerinde değişiklikler yapılarak uyumun optimize edilmesini ifade etmektedir. Bir hidrolojik modelin kalibrasyonu genellikle deneme yanılma metoduyla gerçekleştirilmektedir (Bergström ve Lindström, 2015).

Validasyon; uygunluğu kabul edilmiş parametrelerin, kalibrasyon dışında kalan zaman aralığındaki girdiler ile kullanılarak elde edilen çıktılar üzerinde uygulanması işlemidir. Validasyon bir anlamda parametrelerin, dolayısıyla modelin doğrulanmasıdır.

Kalibrasyon çalışmalarını değerlendirmek için gözlenen ve modellenen değerlerin uyumunu anlamlandırmak amacıyla farklı kriterler kullanılmaktadır. Hidrolojik Modeller için bu kriter genellikle Nash-Sutcliffe (NSE) model verim kriteridir. Model verimleri aynı zamanda hidrolojik modeler için amaç fonkisyonu anlamına da gelmektedir. $\mathrm{R}_{\text {eff }}$ olarak tanımlanan amaç fonkisyonu logaritmik, maksimum, minimum ve ağırlıklı değerler üzerinden hesaplanabilmektedir.

$\operatorname{Reff}=1-\frac{\sum(Q \operatorname{sim}(t)-Q o b s(t))^{2}}{\sum(Q o b s(t)-\overline{Q o b s}(t))^{2}}$

Bu çalışma kapsamında, Manyas Gölü Yukarı Havzası'nda 5 farklı amaç fonksiyonu ( $\mathrm{R}_{\text {eff }}, \operatorname{LogR}_{\text {eff }}, P_{\text {eakR }} R_{\text {eff }}, 0.5 R_{\text {eff }}$ + 0.5 PeakR $R_{\text {eff }}$ ve $0.5 R_{\text {eff }}+0.5 \log _{\text {eff }}$ ) kullanılarak modelin kalibrasyonu yapılmıştır.

Uygulamada, 2003-2015 hidrolojik yılları baz alınmış olup bu aralığın farklı hidrolojik dönemleri (kurak, yağışlı, normal) içermesi ve ön çalışmayla birlikte en verimli sonuçları veren periyot olması maksadıyla 2007-2011 yılları arasında kalibrasyon dönemi seçilmiştir. 2003-2006 ve 2012-2015 yılları arasında modelin validasyonu gerçekleştirilmiştir. 
Bu çalışma sonucunda elde edilen optimum amaç fonksiyonu ve bu diğer amaç fonksiyonlarına göre verim değerleri Çizelge 1'de verilmekte olup 2012-2015 yılları arasındaki validasyon sonuçları gösteren hidrograf karşılaştırması Şekil 4'te verilmektedir.

Çizelge 1. Optimum olarak belirlenen Amaç Fonksiyonu Sonuçları.

\begin{tabular}{|c|c|c|c|c|c|c|}
\hline Amaç Fonksiyonu & Yil & $\begin{array}{c}\text { Ağırlıklı } \\
\mathbf{R}_{\text {eff }}\end{array}$ & $\mathbf{R}^{2}$ & $\mathbf{R}_{\text {eff }}$ & $R_{\text {eff }}$ Peak & $\log R_{\text {eff }}$ \\
\hline \multirow{3}{*}{$\begin{array}{c}0.5 R_{\text {eff }} \\
+ \\
0.5 \text { LogR }_{\text {eff }}\end{array}$} & $\begin{array}{c}2003-2006 \\
(\mathrm{val})\end{array}$ & 0.68 & 0.63 & 0.62 & 0.31 & 0.73 \\
\hline & $\begin{array}{c}2007-2011 \\
(\mathrm{kal}) \\
\end{array}$ & 0.66 & 0.70 & 0.60 & 0.55 & 0.72 \\
\hline & $\begin{array}{c}\begin{array}{c}2012-2015 \\
\text { (val) }\end{array} \\
\end{array}$ & 0.57 & 0.67 & 0.51 & 0.32 & 0.76 \\
\hline
\end{tabular}

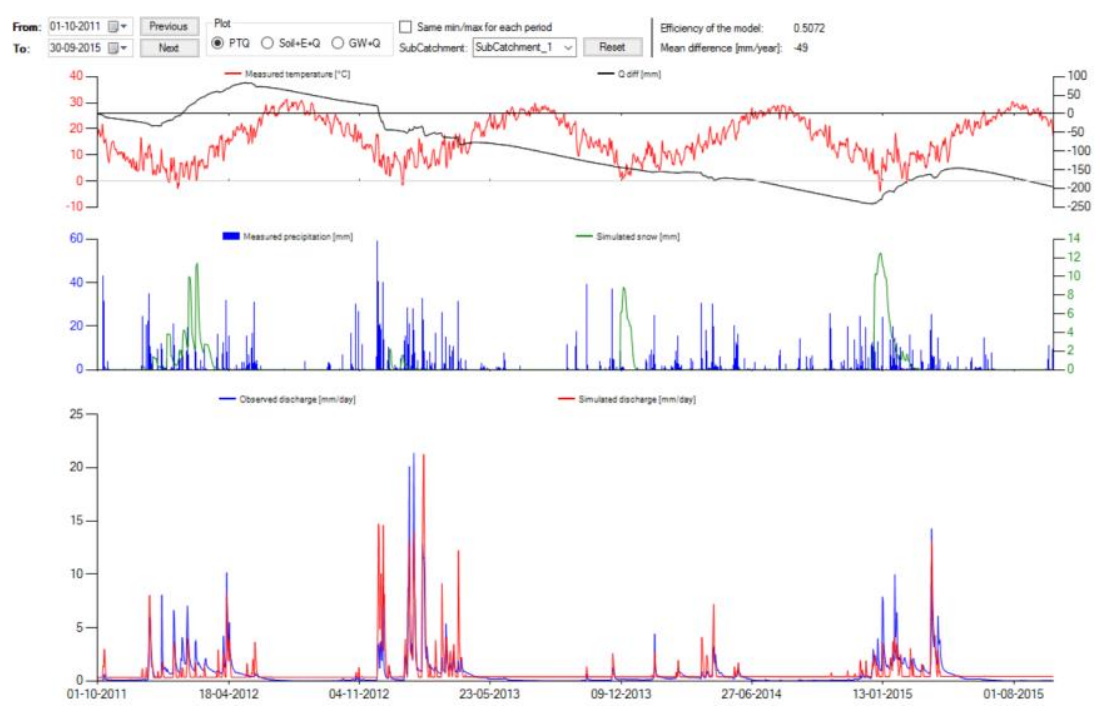

Şekil 4. 2012-2015 yılları validasyon sonuçları.

Kalibrasyon sonucu elde edilen parametrelerin doğrulanmasının yanında bu çalışma kapsamında gerçekleştirilen 2012-2015 dönemleri arasında üretilen model sonuçlarının, uzaktan algılama yöntemleri kullanılarak elde edilen toprak nemi ve karla kaplı alan verileri ile doğrulanması işlemi gerçekleştirilmiştir.

\subsection{Uzaktan Algılama Verileri}

Dünyada uydu görüntülerinin işlenerek birçok çalışmada kullanılması günümüzde oldukça yaygınlaşmıştır. Bununla birlikte su kaynakları ve bileşenlerine dair verilerin toplanması kapsamında da önemli hava merkezleri ve kuruluşlar uydu görüntüleri verileri sağlamaktadır. Bu kapsamda, bu çalışmada yer alan karla kaplı alan verisi, Dünya'daki hava ve deniz olaylarını araştırması amacıyla Amerika Birleşik Devletleri'nin bir kurumu olan Ulusal Okyanus ve Atmosfer Dairesi (The National Oceanic and Atmospheric Administration (NOAA))'nden temin edilmiştir. 2013-2015 hidrolojik yıllarına ait toprak nemi verisi ise Orta Ölçekli Hava Tahminleri için Avrupa Merkezi (The European Centre for Medium-Range Weather Forecasts (ECMWF)) uydu görüntülerinden elde edilerek 4 farklı yüksekliğe ait katman olarak kullanılmıştır.

\section{SONUÇLAR}

Bu çalışma ile Manyas Gölü Yukarı Havzası'nda gerçekleştirilen hidrolojik modelleme uygulamasından elde edilen toprak nemi ve karla kaplı alan verileri, uzaktan algılama yöntemleri kullanılarak uydu görüntülerinden elde edilen veriler ile karşılaştırılmıştır.

Model ve gözlem sonuçları arasında karla kaplı gün sayıları dikkate alınarak yapılan değerlendirme kapsamında Şekil 5’te 2012-2015 hidrolojik yılları kış aylarındaki karlı kaplı alan karşılaştırılmaları görülmektedir. 
A. Uğurluoğlu ve A. Şorman: Hidrolojik Modellemede CBS ve Uzaktan Algılama Tekniklerinin Kullanılması
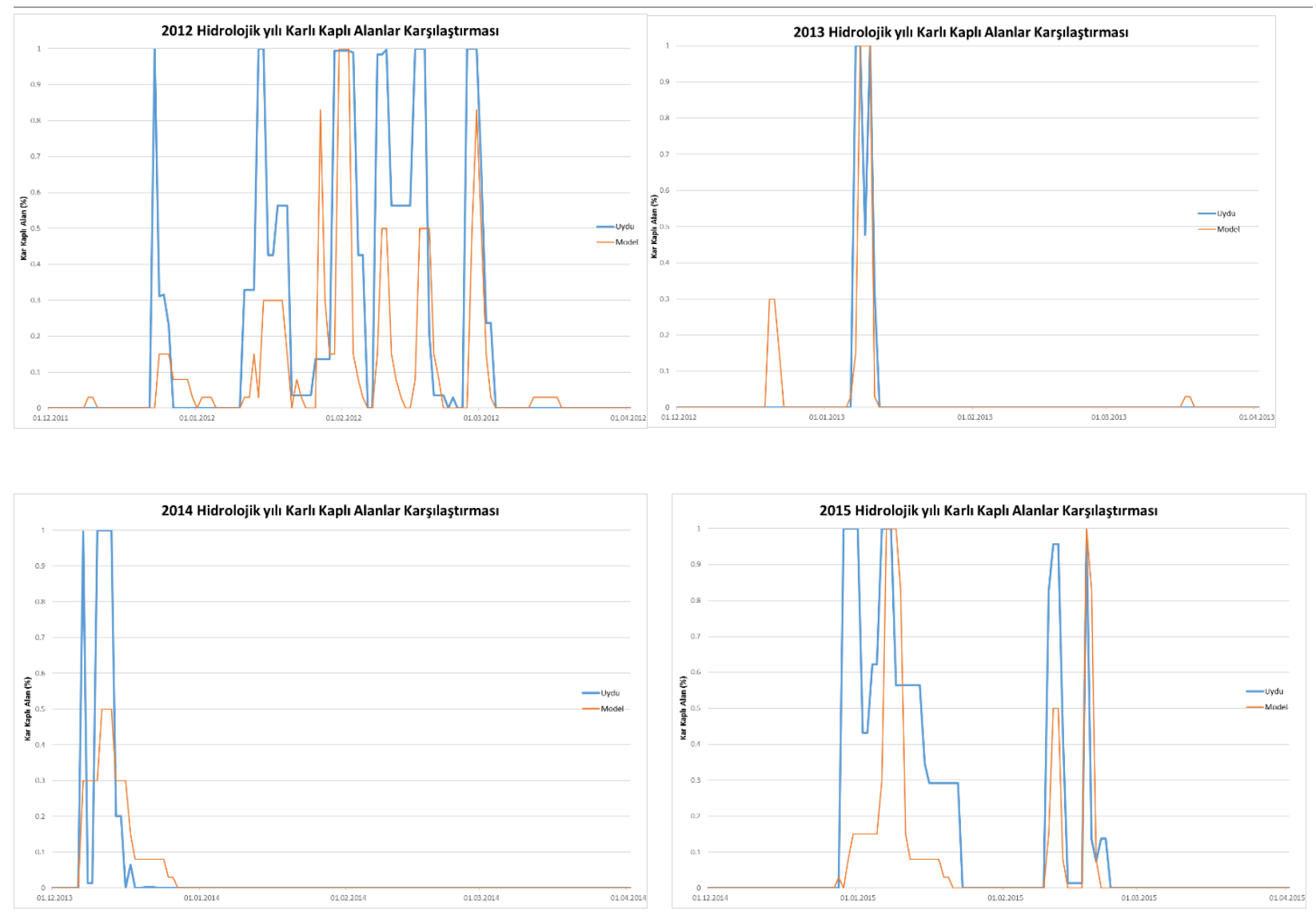

Şekil 5. 2012-2015 su yllı kar kaplı alan karşılaştırması.

Mertebe ve genel eğilim açısından model sonuçları ile gözlem değerleri uyuşmaktadır. Bununla birlikte, gözlem ve model sonuçlarında yer alan karla kaplı gün sayıları arasındaki yüzdesel ilişki kar bulunması muhtemel olan 01 Aralık01 Haziran ayları (184 gün) göz önüne alınarak 2012, 2013, 2014, 2015 yılları için sırasıyla \%93, \%98, \%98, \%97 olarak bulunmuştur. Bu değerler, modelin kar modülünün yüksek doğrulukla çalıştığını göstermektedir.

2013-2015 hidrolojik yılları toprak nemi verisine ilişkin model ve uydu görüntü karşılaştırma sonuçları Şekil 6'da verilmektedir.

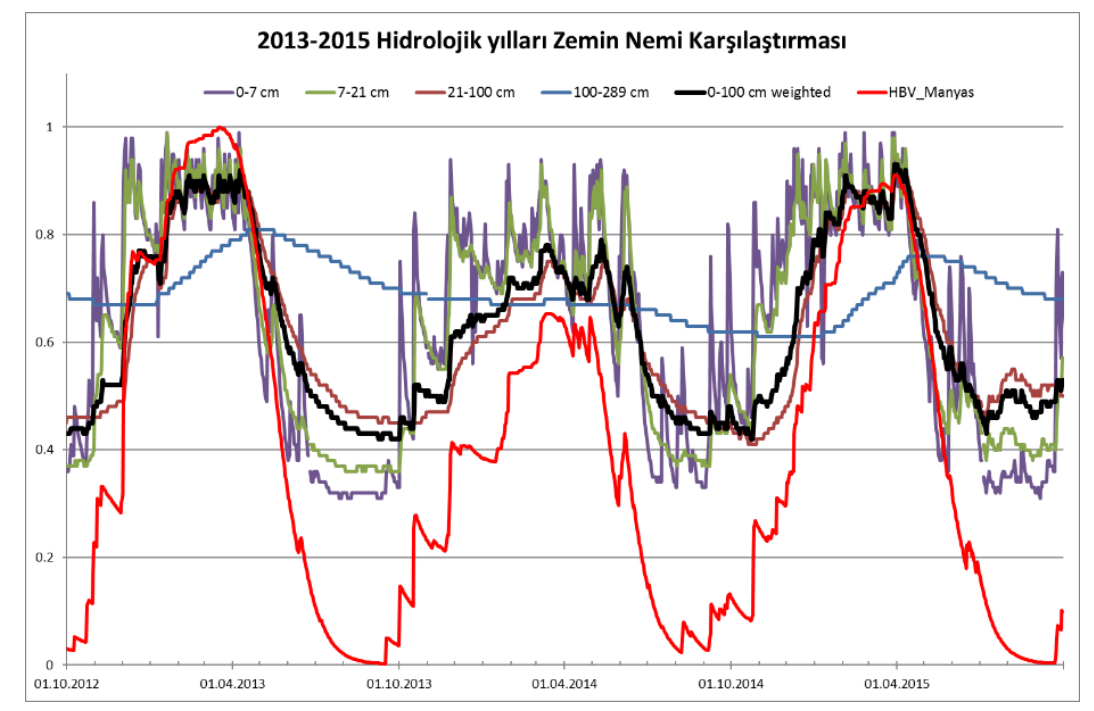

Şekil 6. 2013-2015 su yllı toprak nemi karşılaştırması. 
Şekil 6'da verilen grafikten de görüleceği üzere, bir metreye kadar gözlemlenen ortalama toprak nemi ve model sonuçları mertebe ve eğilim bakımından, özellikle kış ve bahar aylarında birbirine uyum göstermektedir. Yaz aylarında toprak modülünün, toprak nemi değerlerini 0'a yaklaştırdığını göstermektedir. Bu durumun modelin toprak nemine etkiyen parametrelerinden kaynaklandığı düşünülmekte olup etkilerinin gözlenmesi için ayrı bir çalışma yapılması gerekmektedir. Bununla birlikte, toprak nemi atımlarının ortak eğilimde olması, toprak modülünün doğru çalışığını göstermektedir. Çalışma alanı için gözlem değerlerinin toprak neminin \% 40 'ın altına düşmediğini göstermektedir. Bu durum modelin toprak nemini bir eşik değer parametresi ile sınırlandırması gerektirdiği düşüncesini ortaya koymaktadır.

\section{TEŞEKKÜR}

Yazarlar, modelleme çalışmasında gerekli verilerin temini konusunda kolaylık sağlayan Devlet Su İşleri Genel Müdürlüğü ve Meteoroloji Genel Müdürlüğü kurumlarına teşekkür eder.

\section{KAYNAKLAR}

Bergström, S. (1976). Development and application of a conceptual runoff model for Scandinavian catchments. İsveç: Swedish Meteorological and Hydrological Institute.

Bergström, S. ve Lindström, G. (2015). Interpretation of runoff processes in hydrological modelling-experience from the HBV approach. Hydrological Processes, 29 (16), 3535-3545.

Chong-yu, X. (2006). Chapter 1 Modellıng In Hydrology, Hydrologıc Models (s. 1-1, 1-11). UPPSALA: Uppsala University Department of Earth Sciences Air and Water Sciences.

Mulvany, T. (1850). On the use of self-registering rain and flood gauges in making observations of the relations of rain fall and of flood discharges in a given catchment (s. 18-33). Dublin: Proceedings of the Institution of Civil Engineers of Ireland.

Normand, S., Konz, M., ve Merz, J. (2010). An application of the HBV model to the Tamor Basin in Eastern Nepal. Journal of Hydrology and Meteorology, 49-58.

Primožič, M., Kobold, M., ve Brilly, M. (2008). The Implementatıon Of The Hbv Model On The Sava Rıver Basin. IOP Conference Series: Earth and environmental science.

Xiong, L., \& Guo, S. (1999). Two-parameter monthly water balance model and its application. Journal of Hydrology, $111-123$. 